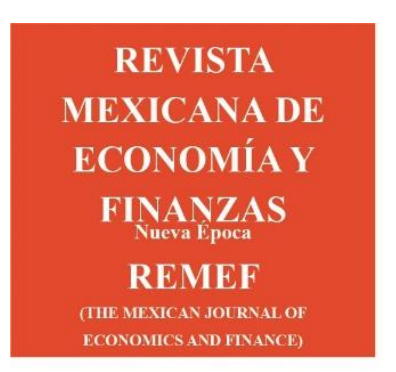

Revista Mexicana de Economía y Finanzas, Nueva Época

Volumen 16 Número 3, Julio - Septiembre 2021, pp. 1-21, e642

THE ECONOMICS AND FINANCE EFFECTS OF THE COVID-19 PANDEMIC Editor: Dr. Ignacio Perrotini

DOI: https://doi.org/10.21919/remef.v16i3.642

(Recibido: 28/febrero/2021, aceptado: 22/junio/2021, publicado: 24/junio/2021)

\title{
Efecto de la educación en la precarización del trabajo en tiempos de la COVID-19 en México
}

\author{
Eduardo Rodríguez Juárez ${ }^{1}$ - Universidad Autónoma del Estado de Hidalgo, México
}

Esta investigación analizó la relación entre la precarización de las condiciones laborales y el nivel de educación de los trabajadores mexicanos, en los primeros meses de la crisis sanitaria por COVID-19 en México. A través de un análisis sectorial y con datos de panel, para los meses de abril, mayo y junio del 2020, se construyó un índice para evaluar la precariedad laboral en los sectores económicos y se estimó un modelo econométrico para analizar la interacción entre las variables de estudio. Se encuentra que la crisis sanitaria por COVID-19 incrementó la precariedad laboral. Situación que hace imprescindible la construcción de políticas laborales-sectoriales. Su principal restricción es la información, la cual todavía es escasa y limitada en el tiempo. La originalidad de este estudio es su enfoque sectorial y su principal aporte es la evidencia de una relación positiva entre los sectores con mayor precarización y los trabajadores con menores credenciales educativas.

Clasificación JEL: I21, J01, J08, J30, J81, J82.

Palabras clave: Precariedad Laboral, educación, crisis sanitaria, COVID-19.

\section{Effect of education on the precariousness of work in times of COVID-19 in Mexico}

In this research, the relationship between the precariousness of working conditions and the education level of workers has been analyzed, for the months of the health crisis due to COVID-19 in Mexico. Through a sectorial analysis and using panel data in the months of April, May and June 2020 and in order to assess the occupational precariousness, an index was built and an economic model was estimated with the purpose of analyzing the interaction among the study variables. It was found that the health crisis due to COVID-19 increased the occupational precariousness. This cogency is the basis for the labor and educational policies. It is limited by the information which is still scarce and limited in time. The originality of this research is its sectorial approach and its main contribution is the cogency of a positive relationship among the sectors with higher precariousness and workers with lower educational credentials.

JEL Classification: I21, J01, J08, J30, J81, J82.

Keywords: Occupational precariousness, education, health crisis, COVID-19.

\footnotetext{
${ }_{1}^{1}$ Autor de correspondencia. Circuito la Concepción KM 2.5 Col. San Juan Tilcuautla, San Agustín Tlaxiaca Hgo., CP. 42160 Teléfono: 7717172000 Ext 4120 eduardor@uaeh.edu.mx; ORCID: https://orcid.org/0000-0002-2232-7544

*Sin fuente de financiamiento para el desarrollo de la investigación
} 


\section{Introducción}

La precariedad en las condiciones de trabajo representa el efecto más palpable de la reconfiguración del sector laboral, en el capitalismo actual. Tras el abandono del Estado de Bienestar, los empleos estables y las altas remuneraciones se han convertido en el más grande anhelo de los trabajadores, sobre todo, ante la implementación de políticas de competencia y flexibilización en el mercado de trabajo (Anisi, 2005). La situación que se vive en el mundo del trabajo ha estado caracterizada por empleos mal remunerados, sin contratos escritos que den estabilidad y certidumbre, además, presentan jornadas laborales excesivas que como lo señala Mendoza et al., (2020) afectan la salud de los trabajadores. Masdonati, Fedrigo, y Zufferey, (2020), argumentan que contar con un trabajo precario no solo implica condiciones hostiles en el puesto sino, además, las aspiraciones educativas para los trabajadores precarios se tornan cada vez más complejas. La precariedad laboral condena a miles de asalariados a la exclusión y marginación social; sus estragos, son cada vez más visibles y ante la crisis sanitaria y económica derivada de la COVID-19, se recrudecen.

La pandemia mundial generada por la enfermedad COVID-19 provocó que el desempeño económico se redujera. El confinamiento social y el cierre de las actividades no esenciales, principal estrategia para contener los contagios de la enfermedad, ocasionó una caída en la producción y en la demanda de bienes a nivel agregado y sectorial. La Comisión Económica para América Latina y el Caribe (CEPAL) en su informe especial sobre COVID-19 (2020), reportó que actividades como la aviación, el turismo y el comercio; enfrentaron una reducción de sus ingresos y una importante pérdida de puestos de trabajo y de condiciones laborales. Shrestha et al., (2020); identificaron que las naciones con mayores pérdidas económicas son las dedicadas al turismo en las cuales se encuentra México, argumento que coincide con lo encontrado por Campos-Vázquez, y Esquivel, (2021); quiénes identificaron que para el caso de México la reducción en el consumo, trajo una caída fundamental en las actividades turísticas. La crisis económica derivada por el virus SARS-Cov2 golpeó con mayor intensidad a los trabajadores con menores condiciones laborales, quienes fueron los primeros en perder sus empleos; no obstante, que de acuerdo con López (2020), muchos de los que lograron conservar sus puestos de trabajo tuvieron que ceder algunas prestaciones, con el fin de no ver rescindido su contrato gremial.

La crisis de la COVID-19 mostró la vulnerabilidad de los trabajadores para hacer frente a situaciones externas, como la provocada por la pandemia; principalmente en aquellas economías que habían promovido la flexibilidad laboral misma que de acuerdo con Rodríguez y Gaona (2020), se dio a partir del detrimento de las condiciones laborales. La forma de afrontar la crisis del trabajo en cada una de las economías a nivel mundial estuvo restringida por las condiciones laborales de su población. Por ejemplo, en países como España e Italia fue posible imponer un confinamiento obligatorio, gracias a los esquemas sociales y laborales que garantizaban la estabilidad económica de su población, por algún tiempo. Este esquema no representaba una opción para países con alta informalidad y vulnerabilidad laboral, como es el caso de México y muchos otros países latinoamericanos, donde salir de sus casas para realizar sus actividades laborales era imprescindible para sobrevivir durante la pandemia (Vázquez y Rodríguez, 2020).

Con el cierre de las actividades no esenciales derivado de la COVID-19, se observa que no todos los trabajadores presentan el mismo grado de precariedad en sus puestos de trabajo. Rodríguez 
(2018), muestra que una característica del sistema económico capitalista es la diferenciación en los procesos distributivos, la cual se modifica de un sector de actividad económico a otro. De acuerdo con Cimoli y CEPAL, (2005), desde antes de la crisis sanitaria existe evidencia suficiente para señalar diferencias en las condiciones de trabajo de los sectores de actividad económica, estas diferencias se explican en función del nivel de desarrollo científico y tecnológico que ostentan los sectores económicos y que condicionan la contratación de trabajadores en función de sus cualificaciones.

La educación es la manera de fortificar las capacidades, habilidades y competencias requeridas para impulsar el desarrollo tecnológico, necesarios para el crecimiento (Melamed y Miranda, 2016). No solo representa la base del conocimiento; además, es una de las formas de mejorar los incentivos laborales de los trabajadores al prepararlos para el mundo del trabajo. Si bien, la precarización de las condiciones de trabajo ha alcanzado a casi todos los trabajadores del mundo; aquellos que se distinguen por poseer mayores niveles de escolaridad han sido menos afectados (Llorente-Heras, 2020), incluso; en economías emergentes como es el caso de la economía mexicana.

En México el primer incidente de la enfermedad por COVID-19 se presentó el 27 de febrero de 2020, no obstante; fue hasta el 27 de marzo que se publicó en el Diario Oficial de la Federación (DOF) el cierre de las actividades no esenciales y confinamiento social con una vigencia del 30 de marzo al 30 de abril, sin embargo, ante el avance de la enfermedad, las autoridades sanitarias extendieron esta suspensión hasta el 15 de mayo, fecha en que se pública en el mismo órgano informativo la reapertura de algunas actividades a partir del primero de junio (DOF, 2020). En este sentido, el segundo trimestre del año 2020 es crucial para comprender los efectos económicos generados por la COVID-19 en los sectores económicos del país; y observar las consecuencias que ha tenido el confinamiento social sobre los empleos de los trabajadores mexicanos.

Ante la situación descrita con antelación, el objetivo de este artículo fue analizar la relación entre el nivel de educación de los trabajadores mexicanos y la precarización de las condiciones laborales en los primeros tres meses de la crisis sanitaria por la COVID-19, a través; de un modelo econométrico de datos panel se muestra la interacción entre la precariedad laboral y los niveles de educación, con el propósito de generar acciones que coadyuven a mejorar la calidad de las condiciones laborales. Para el desarrollo de la investigación se utilizó la información de la Encuesta Telefónica de Ocupación y Empleo (ETOE), publicada por el Instituto Nacional de Estadística y Geografía (INEGI) para los meses de abril, mayo y junio, considerados los meses de mayor impacto en la actividad económica y en la estructura laboral.

El trabajo se encuentra organizado de la siguiente manera: en la primera parte se presenta la discusión sobre la importancia del estudio de la precarización en las condiciones de trabajo, sus antecedentes y formas de abordar el problema. En el segundo punto se muestran las características laborales y educativas de la población ocupada en México durante el año 2020, resaltando la información de los meses de abril, mayo y junio, los cuales corresponden al confinamiento social obligatorio. El tercer apartado presenta el índice de precariedad laboral, así como el modelo utilizado para demostrar la relación inversa entre educación y precariedad en los meses más impactantes de la pandemia. Por último, se presentan las consideraciones finales del estudio. 


\section{Algunos aspectos de la precariedad laboral}

El respeto a los derechos de los trabajadores ha sido parte de la agenda de desarrollo de todos los países. Desde 1999, en la Reunión Regional de los Estados Miembros de la Organización Internacional del Trabajo (OIT), titulada "trabajo decente y protección para todos: prioridad de las Américas"; se estableció como una de las necesidades más inmediatas fomentar la creación del trabajo decente, en la región (OIT, 1999). Gálvez et al., (2011), señalaron que el trabajo decente refiere a un término en construcción, de carácter integrador y de amplio contenido ético y de justicia social; un empleo decente, es aquel que cuenta con dos características: buena remuneración y protección, elementos que se reflejan en las Condiciones de Trabajo (CT). Rodríguez y Gaona (2020), mostraron que las CT son factores que la empresa otorga al trabajador y que influyen en su salud y bienestar, incidiendo en el tiempo de trabajo y en su organización.

Las CT influyen en la productividad y por tanto en el tiempo que el trabajador destina a sus actividades laborales. De acuerdo con Rolle (2005), las empresas demandan un trabajo efectivo, el cual es diferente al trabajo establecido; mientras uno se manifiesta en el contrato, el otro se expresa en el producto generado, el cual depende de las condiciones que la empresa otorgue a sus trabajadores. Las CT son un elemento que contribuye a la distribución de la riqueza la cual debe edificarse "... en torno a una lógica de derechos y a un principio de igualdad de acceso a cierto número de bienes considerados fundamentales" (Piketty, 2014, p. 529), en los que se encuentran el salario y las prestaciones sociales.

La precariedad laboral es resultado de las pretensiones de una mayor ganancia por parte de las empresas, a través del mecanismo más simple, pero a su vez, el más doloroso para los trabajadores; la reducción del salario y de sus condiciones de trabajo, con lo que se amenazan la estabilidad laboral y la cohesión social, haciendo del futuro algo cada vez más incierto, que, aunado al abandono del estado de Bienestar encargado de dar protección a los asalariados han incrementado los niveles de pobreza laboral en las economías del mundo. Además, el desempleo y la incapacidad del mercado de trabajo para absorber la mano de obra disponible crea las condiciones necesarias, para precarizar aún más las actividades laborales (De Oliveira, 2006).

La precarización laboral refiere a la perdida continua de garantías que hacen del trabajo un elemento inseguro, que afecta de manera directa a los trabajadores y sus familias. Se trata de empleos establecidos por debajo de una norma social aceptada y que considera una serie de dimensiones como: la temporal, la organizacional, la económica y/o social (Martínez-Licerio, et al., 2019). Los estudios de la precarización laboral cobraron fuerza a partir de la decada de los noventa, cuando con el fin de fortalecer los derechos laborales y dignificar el empleo, la OIT, promovió el programa del trabajo decente; el cual, busca contribuir al logro de un trabajo digno productivo, con equidad, seguridad y dignidad humana (Gálvez et al., 2011). Si bien, algunos países han logrado avances en la promoción del trabajo decente; en México, los esfuerzos por lograr dicho objetivo parecen ser insuficientes, sobre todo cuando nos enfrentamos a factores atípicos como el ocurrido con la crisis sanitaria y económica generada por la COVID-19 durante el año 2020, la cual impulsó el efecto adverso al trabajo decente: la precarización de las condiciones laborales.

Los esfuerzos por comprender y mitigar el fenómeno de la precariedad laboral han sido bastos; no obstante, no se cuenta con una metodología única para precisar el grado de precariedad 
en las CT que presentan los trabajadores, por ejemplo: en el 2001, la OIT hizo su primera propuesta estudiando a 15 países, utilizando variables como: empleo, ingresos, y protección social (OIT, 2001). Gálvez, et al., (2011), presentaron una propuesta de construcción del índice de trabajo decente utilizando como base de datos a la población ocupada del estado de Nuevo León para el año 2007. En su planteamiento los autores utilizaron tres indicadores: empleo, derechos laborales y prestaciones.

De Oliveira (2006), propuso la construcción de un índice de precariedad laboral/calidad laboral, a través de un análisis factorial utilizando 6 indicadores, que obtiene de la Encuesta Nacional de Juventud 2000: si la firma cuenta con local, si se cuenta con contrato escrito, tipo de prestaciones, horas trabajadas, relación de los estudios con las actividades desarrolladas, e ingresos. Por su parte, García, (2009); construye un índice de precariedad analizando la situación laboral en 32 ciudades mexicanas haciendo uso de la ENOE para el año 2006. Estudia la precariedad a través de la ausencia de contratos de trabajo y de protección social, desempleo, extendida presencia de los trabajadores por cuenta propia y de los micronegocios, los bajos niveles de ingreso las jornadas parciales y los niveles de sindicalización.

Pineda (2019), desarrolló un índice simple de precariedad laboral para los años 2006 y 2010, utilizando cuatro variables: jornada laboral, salario mínimo, estabilidad y cotizaciones al seguro social. Por su parte, Mendoza, et al., (2020); utilizaron cinco condicionantes de precariedad laboral: sin sindicato, jornada precaria, sin prestaciones, sin seguridad social y contrato precario, utilizando una metodología de grupos para identificar los niveles y subniveles, lo que permitió ordenar los resultados obtenidos. Todas las propuestas aquí señaladas tienen como característica tres indicadores comunes: Ingresos, prestaciones y jornada laboral; la diferencia se encuentra en el nivel de desagregación de la variable, además, existen otros indicadores que pueden considerarse en función de la población objeto de estudio; es decir, si consideramos el total de la población ocupada o de la población asalariada.

\section{Características laborales y educativas de los trabajadores mexicanos}

En México el virus SARS-CoV-2 expuso la vulnerabilidad en la que se encontraban miles de trabajadores previo a la emergencia sanitaria. Por ejemplo, de acuerdo con la Encuesta Nacional de Ocupación y Empleo (ENOE) para el primer trimestre del 2020, poco más de 31 millones de trabajadores se encontraban en la informalidad, es decir el 56\% de la Población Ocupada (PO) de México no gozaban de un empleo formal; lo que significaba no contar con algún esquema de seguridad social como: servicio médico, fondo de ahorro para el retiro, créditos a la vivienda, o alguna otra prestación que ampliara las posibilidades de hacer frente a la pandemia, ante la estrategia de confinamiento social impulsada por el gobierno federal.

El cierre de las actividades no esenciales provocó que varios trabajadores perdieran su empleo o vieran reducidos sus ingresos. De esta manera, durante los meses más severos de la crisis sanitaria (abril, mayo y junio); los efectos por la pandemia fueron distintos para cada trabajador y se observó una fuerte relación entre la calidad del empleo y los niveles de educación que posee la PO. Las credenciales educativas fueron un determinante para caer en una situación de precariedad o desempleo, la PO con niveles educativos medios y superiores creció en un $2.8 \%$ del primero al segundo trimestre del 2020. En contra parte, la PO con nivel de estudios de primaria y secundaria se 
redujo en 2.8 y 1.6\% respectivamente; mientras que la PO sin primaria terminada, no presentó variación alguna en el período señalado.

Es cierto que la relación condiciones de trabajo-empleo-educación no es homogénea para los 20 sectores de actividad económica que de acuerdo con el Sistema de Clasificación Industrial de América del Norte (SCIAN), ${ }^{2}$ conforman la economía mexicana (tabla 1). Dutrénit (2015), señala que, con la automatización, la computación, el software, la detección y las redes; se hace indispensable contar con mano de obra cuyos niveles educativos sean acordes a las exigencias laborales. La implementación a nivel mundial del confinamiento social y cierre de actividades no estratégicas ${ }^{3}$ modificó la forma de operar el empleo, el teletrabajo se vislumbró como la manera más eficiente para desarrollar las actividades laborales durante la pandemia (Peiró y Soler, 2020).

Tabla 1. Clave SCIAN de los sectores de actividad económica de México

\begin{tabular}{|c|c|c|c|}
\hline $\begin{array}{l}\text { Clave } \\
\text { SCIAN }\end{array}$ & Sector de Actividad Económica & $\begin{array}{l}\text { Clave } \\
\text { SCIAN }\end{array}$ & Sector de Actividad Económica \\
\hline 11 & $\begin{array}{l}\text { Agricultura, ganadería, aprovechamiento } \\
\text { forestal, pesca y caza }\end{array}$ & 53 & $\begin{array}{l}\text { Servicios inmobiliarios y de alquiler de } \\
\text { bienes }\end{array}$ \\
\hline 21 & Minería & 54 & $\begin{array}{l}\text { Servicios profesionales, científicos y } \\
\text { técnicos }\end{array}$ \\
\hline 22 & $\begin{array}{l}\text { Generación y distribución de } \\
\text { electricidad, suministro de agua y gas }\end{array}$ & 55 & Corporativos \\
\hline 23 & Construcción & 56 & $\begin{array}{l}\text { Servicios de apoyo a los negocios y } \\
\text { manejo de desechos }\end{array}$ \\
\hline $31-33$ & Industrias manufactureras & 61 & Servicios educativos \\
\hline 43 & Comercio al por mayor & 62 & Servicios de salud y de asistencia social \\
\hline 46 & Comercio al por menor & 71 & $\begin{array}{l}\text { Servicios de esparcimiento, culturales y } \\
\text { deportivos }\end{array}$ \\
\hline $48-49$ & Transportes, correos y almacenamiento & 72 & $\begin{array}{l}\text { Servicios de hospedaje y de preparación } \\
\text { de alimentos y bebidas }\end{array}$ \\
\hline 51 & Información en medios masivos & 81 & $\begin{array}{l}\text { Otros servicios, excepto actividades } \\
\text { gubernamentales }\end{array}$ \\
\hline 52 & Servicios financieros y de seguros & 93 & $\begin{array}{l}\text { Actividades gubernamentales y de } \\
\text { organismos internacionales }\end{array}$ \\
\hline
\end{tabular}

Fuente: Elaboración propia con base en datos del Sistema de Clasificación Industrial para América del Norte (SCIAN-INEGI).

Los meses de abril, mayo y junio -segundo trimestre del año-, representaron para la economía mexicana los cambios más significativos en los niveles de empleo y en las condiciones de trabajo a nivel sectorial. Durante estos meses, el 90 por ciento de los sectores de la actividad económica

\footnotetext{
2 De acuerdo con INEGI (2021), el SCIAN, es un clasificador de actividades económicas único para la región de América del Norte. Clasifica las actividades económicas de acuerdo al nivel de agrupación, acordadas de forma trilateral por Canadá, Estados Unidos (EE.UU.) y México; la clasificación para el caso mexicano a dos dígitos involucra veinte sectores de actividad económica.

${ }^{3}$ En México, el 27 de marzo del 2020 se publicó en el Diario Oficial de la Federación el cierre de las actividades consideradas como no esenciales del 30 de marzo al 30 de abril con la finalidad de "disminuir la carga de enfermedad, sus complicaciones y la muerte por COVID-19 en la población residente en el territorio nacional” (DOF, 2020)
} 
presentaron una disminución en el nivel de empleo con respecto al primer trimestre del año 2020. Las tres actividades que más redujeron su PO fueron: Corporativos; Servicios de hospedaje y de preparación de alimentos y bebidas; y Minería, con un 64, 62 y 39\% respectivamente; no obstante, al bajo crecimiento de los empleos en las actividades señaladas, tenemos que en dos sectores: Comercio al por mayor y Actividades gubernamentales y de organismos internacionales, el número de trabajadores se incrementó en un 0.81 y 27.16 \% en el período señalado, ver figura 1.

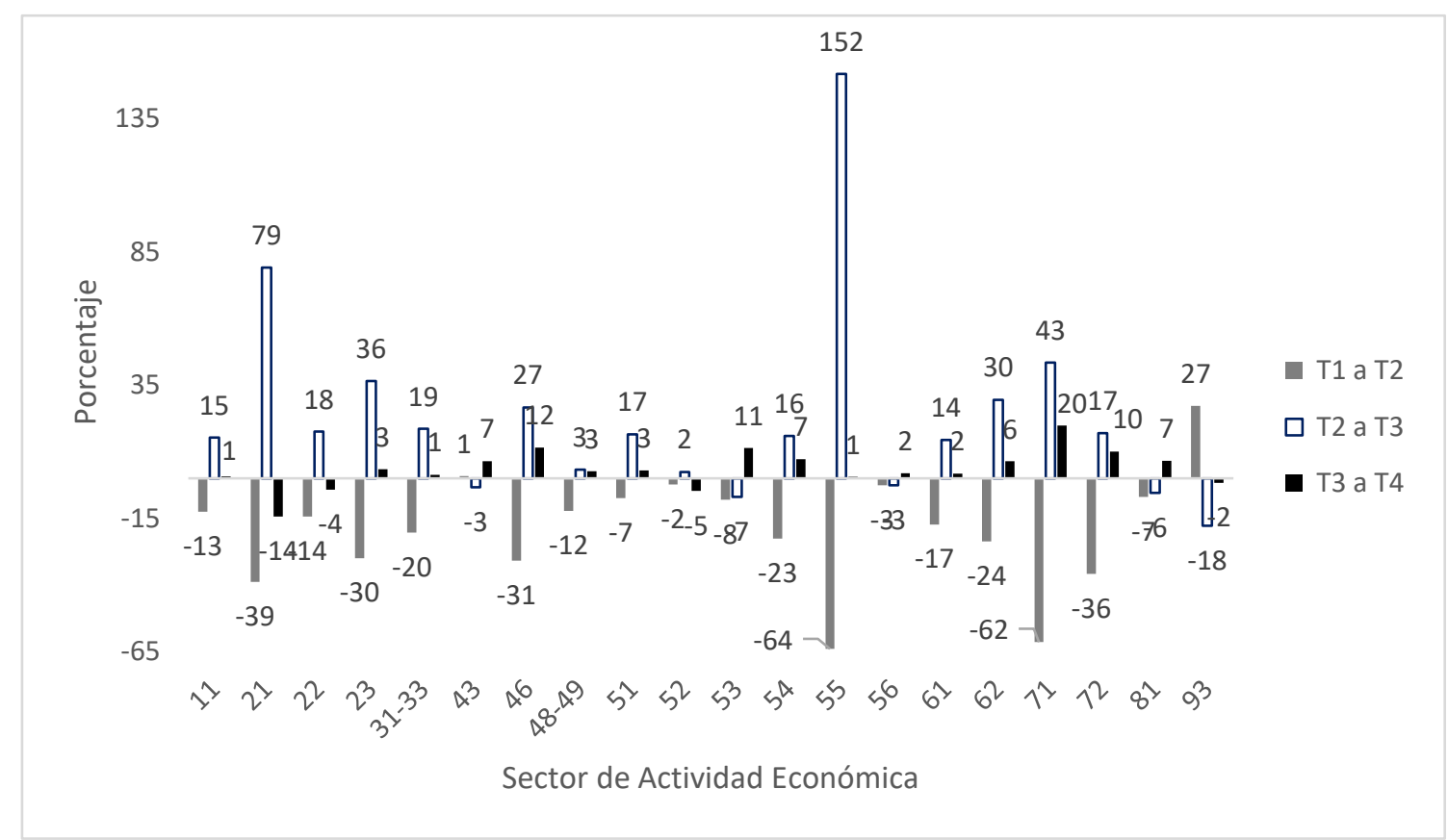

Figura 1. Tasa de crecimiento con respecto al trimestre anterior, población ocupada, año 2020 Fuente: Elaboración propia con base en datos de la ENOE trimestres 1, 3 y 4; y ETOE trimestre 2. INEGI

El crecimiento en el empleo suscitado en el sector 93 (Actividades gubernamentales y organismos internacionales), para el segundo trimestre del año 2020; se fundamenta en las acciones del gobierno al inicio de la contingencia sanitaria, principalmente las relacionadas con el orden público y la seguridad nacional (Fuerzas armadas y Guardia Nacional), las cuales han sido altamente beneficiadas en esta administración (Monroy, 2020). De esta manera, actividades como: administración y aplicación de los recursos públicos; impartición de justicia y el mantenimiento de la seguridad y el orden público; actividades administrativas de instituciones de bienestar social; así como, a las actividades a salvaguardar la seguridad nacional, fueron consideradas esenciales para el desarrollo del país, de acuerdo con el Diario Oficial de la Federación con fecha 30 de marzo del 2020.

Durante los meses de abril, mayo y junio; los principales indicadores de calidad laboral tales como el ingreso, las horas trabajadas y las prestaciones, mostraron marcadas diferencias entre los sectores de actividad económica. Las figuras 2, 3 y 4; relacionan la tasa de crecimiento (decrecimiento) de la PO, con la diferencia entre el porcentaje de trabajadores que: 1) ganan hasta dos salarios mínimos, 2) trabaja más de 48 horas y; 3) no cuentan con prestaciones laborales; durante el periodo señalado. En el primer cuadrante de la figura 2, se muestra un crecimiento de la PO y una diferencia positiva en el porcentaje de trabajadores que perciben hasta dos salarios mínimos. Por ejemplo: el sector 81, Otros servicios, excepto actividades gubernamentales; la PO creció en un 8.4\% 
entre los meses de abril a junio, y el porcentaje de personas que ganan hasta dos salarios mínimos lo hizo en 6.25 puntos porcentuales, es decir; creció el empleo, pero también lo hizo el personal que percibe ingresos de hasta dos salarios mínimos.

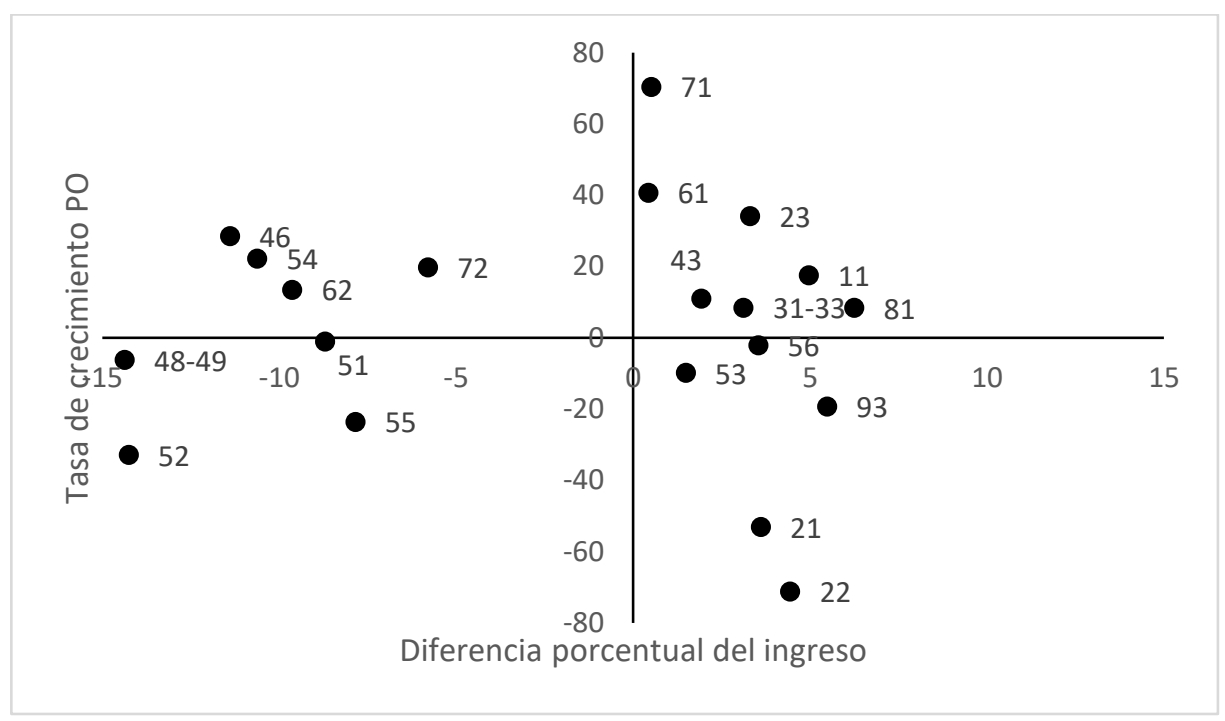

Figura 2. Relación entre la tasa de crecimiento de la PO y la diferencia entre los porcentajes de PO que ganan hasta dos salarios mínimos, abril a junio del 2020

Fuente: Elaboración propia con base en datos mensuales correspondientes al segundo trimestre de la ETOE 2020. INEGI

El segundo cuadrante, muestra una tasa de crecimiento positiva de la PO y una diferencia negativa entre los porcentajes de trabajadores de la variable de estudio. Ejemplo: en el sector 62, Servicios de salud y de asistencia social, la PO creció en un 13.5\%, mientras que la diferencia entre el porcentaje de personas que gana hasta dos salarios mínimos fue de -9.6 puntos porcentuales. En este cuadrante se ubican los sectores económicos que presentan una reducción en el porcentaje de PO que gana hasta dos salarios mínimos. El tercer cuadrante, presenta una disminución de la PO y una diferencia negativa en el porcentaje de la variable de estudio. Consideremos como muestra al sector 52, Servicios financieros y de seguros; en el cual la PO tuvo una tasa de crecimiento negativa del $32.8 \%$ y la diferencia entre los porcentajes de participación de la PO que ganan hasta dos salarios mínimos fue de $-14.2 \%$.

Los sectores localizados en el cuadrante 3 redujeron la participación de la población con ingresos menores. Por último, el cuadrante 4 muestra aquellos sectores en los que la tasa de crecimiento de la PO fue negativa y la diferencia entre el porcentaje de PO que gana hasta dos salarios mínimos es positiva. Ejemplo: En la minería, el empleo cayó del mes de abril a junio en un 53\%, en contra parte la diferencia en el porcentaje de la población que gana hasta dos salarios mínimos se incrementó en 3.61\%. Es decir, el cuadrante 4 ubica a los sectores con el peor de los escenarios, disminución en los niveles de empleo y aumento de la población con ingresos de hasta dos salarios mínimos. Los gráficos 3 y 4 se interpretan de manera análoga, para la PO que trabaja más de 48 horas a la semana y para la PO que no cuenta con prestaciones. 


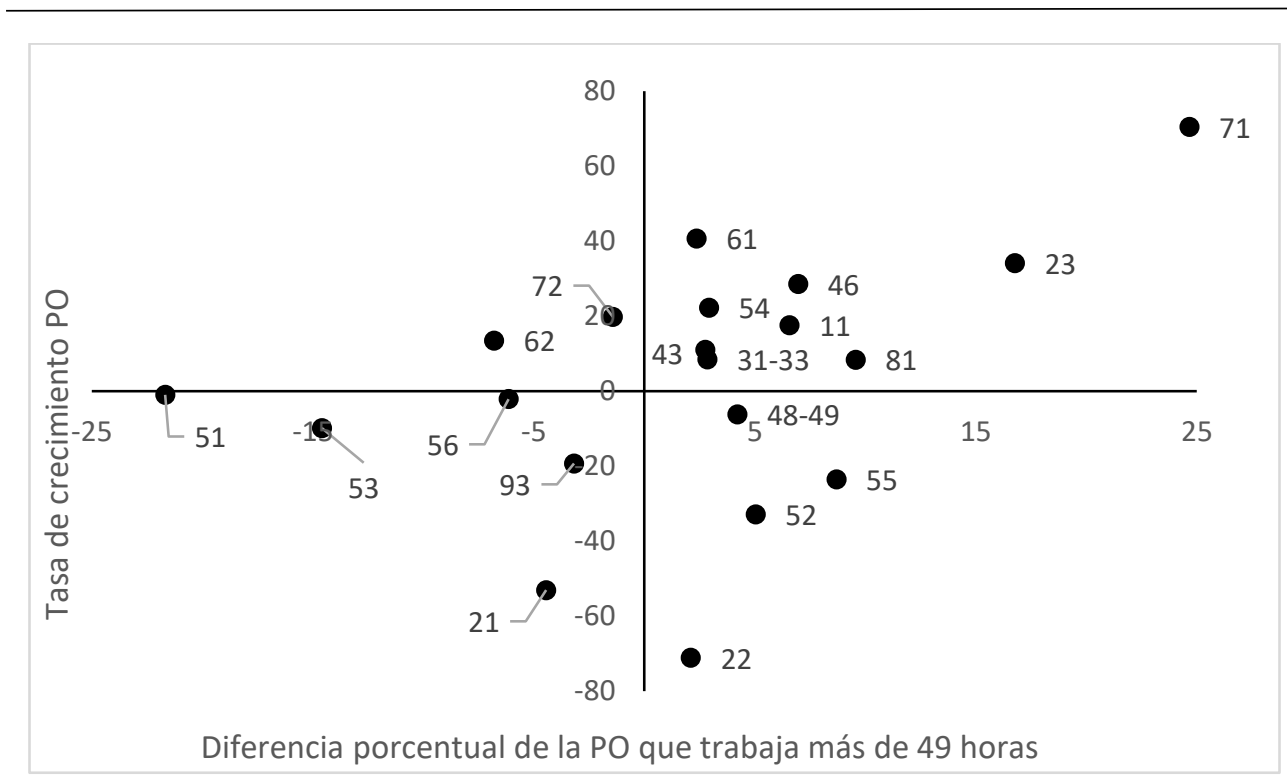

Figura 3. Relación entre la tasa de crecimiento de la PO y la diferencia entre los porcentajes de PO que trabajan más de 48 horas, entre los meses de abril y junio del 2020

Fuente: Elaboración propia con base en datos mensuales correspondientes al segundo trimestre de la ETOE 2020. INEGI

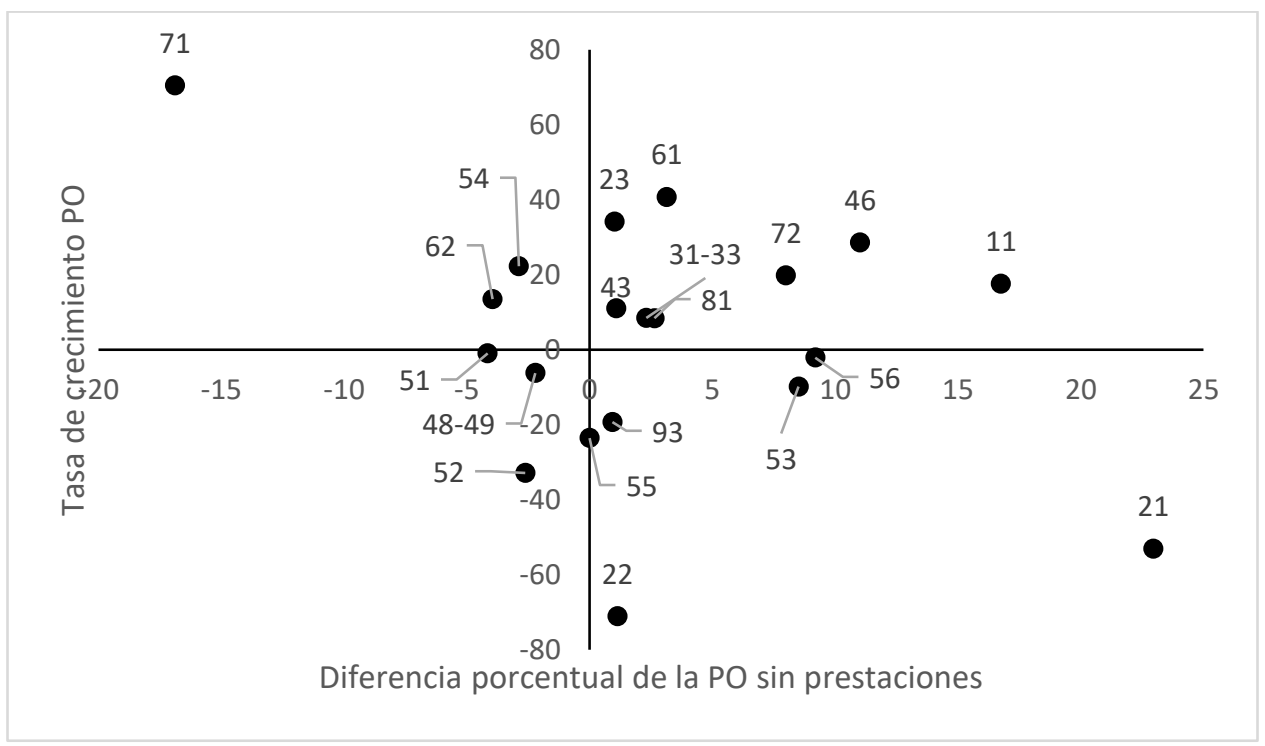

Figura 4. Relación entre la tasa de crecimiento de la PO y la diferencia entre los porcentajes de PO que no cuenta con prestaciones, entre los meses de abril y junio del 2020

Fuente: Elaboración propia con base en datos mensuales correspondientes al segundo trimestre de la ETOE 2020. INEGI

Las características que presentó la PO en los meses de estudio indican un aumento en la precariedad laboral. En general, en los cuadrantes 1 y 4 se localizan los sectores de actividad económica con las condiciones laborales más precarias, en contraste los sectores económicos menos precarios se ubican en los cuadrantes 2 y 3. 


\section{4. Índice de precariedad laboral y modelo econométrico. Propuesta metodológica}

Si bien algunos países han logrado avances en la promoción del trabajo decente; en México los esfuerzos por lograr dicho objetivo parecen ser insuficientes, sobre todo cuando nos enfrentamos a factores atípicos como el ocurrido con la crisis sanitaria y económica durante el año 2020; la cual impulso el efecto adverso al trabajo decente: la precarización de las condiciones laborales. Contar con un parámetro de medición de la precariedad laboral que permitan evaluar el problema es el propósito de este apartado, en el cual se presenta nuestra propuesta de evaluación de la precariedad laboral.

Nuestra propuesta considera el total de población ocupada, con el fin de poder identificar las características del empleo de todos los trabajadores mexicanos en los diferentes sectores de actividad económica para los meses de abril, mayo y junio. La información se obtuvo de la Encuesta Telefónica de Ocupación y Empleo desarrollada por el INEGI, para el segundo trimestre del año 2020. Con el propósito de obtener representatividad de la población a cada una de las variables utilizadas se aplica el factor de expansión proporcionado por la ETOE. Las variables utilizadas para la construcción del índice son:

1. Ingresos. Las remuneraciones provenientes del trabajo son un aspecto esencial para asegurar la calidad de vida de los trabajadores y de sus familias. En esta variable se considera el porcentaje de la población ocupada que percibe una remuneración inferior o igual, a dos salarios mínimos.

2. Jornada laboral. El lapso del tiempo destinado al trabajo es un indicativo de precariedad laboral. Jornadas excesivas y atípicas son perjudiciales para la salud. Una jornada excesiva no solo afecta la vida laboral, sino también la vida familiar al destinar el mayor tiempo al trabajo. Para la operacionalización de esta variable se considera al porcentaje de la población ocupada que trabaja más de 48 horas a la semana.

3. Prestaciones: La seguridad social es uno de los indicadores más importantes para atender y amparar a los trabajadores frente a cualquier imprevisto, además, las prestaciones de ley representan una forma de dignificar el trabajo al distribuir las ganancias entre los trabajadores, a través de: utilidades, prima vacacional y aguinaldo. El contar con un empleo que no proporcione prestaciones de ley, es un indicativo de trabajo precario. Para este indicador, se consideró el porcentaje de la población ocupada que no cuenta con ninguna prestación de ley.

La estandarización de las variables que integran el índice se realiza con la distancia al valor máximo y mínimo. Así, el procedimiento para su estandarización se presenta a continuación:

$$
\widehat{V}_{i j}=\left(\frac{V_{i j}-V_{j \min }}{V_{j \operatorname{máx}}-V_{j \min }}\right) \times 100
$$


Donde:

$\widehat{V}_{j}$ : es el valor estandarizado de la variable $j$ en el sector $i$

$V_{i j}$ : es el valor de la variable $j$ en el sector $i$ en determinado momento;

$V_{j m i n}$ : es el valor mínimo que toma la variable $j$,

$V_{j m a ́ x}:$ es el valor máximo que toma la variable $j$.

Dado que la forma de operar las variables está dada en porcentaje, el valor máximo esta representado por el 100, el cual indica que el total de la población cuenta con la variable de estudio, mientras que el valor mínimo de 0 , expresa que el total de la población no cuenta con la característica de estudio. Una vez desarrollado el proceso de estandarización de las variables, se obtienen las ponderaciones $\alpha_{i}$ de cada variable que compone el índice. Para obtener una clasificación general de la precariedad laboral y en virtud de no existir elementos para considerar la importancia de una variable sobre otra, cada variable fue considerada con la misma importancia $\left(\frac{1}{3}\right)$ de ponderación. La forma de obtener la ponderación de cada componente $C_{i j}$ (con $i=1, \ldots, 20$ y $j=1,2,3$ ); y conformar el Índice de Precariedad Laboral (IPRECAL), para los sectores económicos de México será:

$$
\operatorname{IPRECAL}_{i}=\alpha_{1} C_{i j}+\alpha_{2} C_{i j}+\alpha_{3} C_{i j}
$$

Los resultados del IPRECAL (ecuación 2), se clasifican en 3 estratos (baja, moderada y alta precariedad), lo que permite observar el nivel de precariedad del empleo en los sectores económicos de México, véase tabla 2. La tabla 2, exhibe los resultados del IPRECAL para los meses de abril, mayo y junio del año 2020. Ahí se observa que, en la etapa más enérgica de la contingencia sanitaria, los sectores económicos que precarizaron las condiciones laborales de sus trabajadores son los sectores: 11, 23,46, 48-49, 72 y 81. Correspondientes a la Agricultura, ganadería, pesca y caza; Minería; Comercio al por menor, Transportes, correos y almacenamiento; Servicios de hospedaje y de preparación de alimentos y bebidas. Estos sectores, son considerados de baja tecnificación y por tanto de menor especialización en sus trabajadores. En contra parte los sectores 22, 52, 55, 61 y el 93, referentes a la Generación y distribución de electricidad, suministro de agua y gas; Servicios inmobiliarios y de alquiler de bienes; Corporativos; Servicios Educativos y; Actividades gubernamentales y de organismos internacionales; fueron los que menos precarizaron sus condiciones laborales; además de que son sectores con un mayor requerimiento de mano de obra especializada. El resto de los sectores obtuvo un grado de precariedad moderada. 
Tabla 2. Índice de precariedad laboral para los meses de abril, mayo y junio del 2020

\begin{tabular}{|c|c|c|c|c|c|c|c|c|c|c|c|}
\hline \multirow{2}{*}{$\begin{array}{l}\text { Clave } \\
\text { SCIAN }\end{array}$} & \multirow{2}{*}{$\begin{array}{l}\text { Sector de Actividad } \\
\text { Económica }\end{array}$} & \multirow[t]{2}{*}{ Mes } & \multirow[t]{2}{*}{ Total } & \multicolumn{3}{|c|}{ Porcentaje de población ocupada: } & \multicolumn{3}{|c|}{ Dimensiones } & \multirow[b]{2}{*}{ IPRE } & \multirow[b]{2}{*}{$\begin{array}{l}\text { Grado de } \\
\text { precariedad }\end{array}$} \\
\hline & & & & $\begin{array}{l}\text { Con ingresos de } \\
\text { hasta dos salarios } \\
\text { mínimos }\end{array}$ & $\begin{array}{l}\text { Con jornada } \\
\text { de } 49 \text { horas o } \\
\text { más } \\
\end{array}$ & $\begin{array}{l}\text { Sin } \\
\text { prestaciones }\end{array}$ & 1 & 2 & 3 & & \\
\hline \multirow[t]{3}{*}{11} & \multirow{3}{*}{$\begin{array}{l}\text { Agricultura, ganadería, pesca } \\
\text { y caza }\end{array}$} & Abril & $5,421,646$ & 62.53 & 20.61 & 76.86 & 0.99 & .37 & 0.79 & 0.53 & Alta \\
\hline & & Mayo & $5,456,407$ & 61.06 & 13.96 & 81.47 & 0.99 & .39 & 0.86 & 0.52 & Alta \\
\hline & & Junio & $6,375,759$ & 67.49 & 27.19 & 93.61 & 0.99 & .33 & 0.73 & 0.63 & Alta \\
\hline \multirow[t]{3}{*}{21} & \multirow[t]{3}{*}{ Minería } & Abril & 160,802 & 27.66 & 31.90 & 2.09 & 0.98 & .72 & 0.68 & 0.21 & Moderada \\
\hline & & Mayo & 106,157 & 48.94 & 10.71 & 20.65 & 0.98 & .51 & 0.89 & 0.27 & Moderada \\
\hline & & Junio & 75,505 & 31.27 & 27.46 & 25.04 & 0.98 & 0.69 & 0.73 & 0.28 & Moderada \\
\hline \multirow[t]{3}{*}{22} & \multirow{3}{*}{$\begin{array}{l}\text { Generación y distribución de } \\
\text { electricidad, suministro de } \\
\text { agua y gas }\end{array}$} & Abril & 341,899 & 7.32 & 3.56 & - & 0.97 & 0.93 & 0.96 & 0.04 & Baja \\
\hline & & Mayo & 79,748 & 400 & 19.24 & 3.59 & 0.97 & 0.58 & 0.81 & 0.22 & Moderada \\
\hline & & Junio & 98,736 & 11.76 & 5.67 & 1.13 & 0.97 & 0.88 & 0.94 & 0.06 & Baja \\
\hline \multirow[t]{3}{*}{23} & \multirow[t]{3}{*}{ Construcción } & Abril & $2,642,603$ & 57.72 & 10.99 & 77.44 & 0.96 & 0.42 & 0.89 & 0.49 & Alta \\
\hline & & Mayo & $2,888,656$ & 65.12 & 13.68 & 83.05 & 0.96 & 0.35 & 0.86 & 0.54 & Alta \\
\hline & & Junio & $3,543,668$ & 61.02 & 27.76 & 78.45 & 0.96 & 0.39 & 0.72 & 0.56 & Alta \\
\hline \multirow[t]{3}{*}{$31-33$} & \multirow[t]{3}{*}{ Industrias manufactureras } & Abril & $6,982,002$ & 64.08 & 13.60 & 26.36 & 0.95 & 0.36 & 0.86 & 0.35 & Moderada \\
\hline & & Mayo & $7,172,274$ & 67.06 & 17.95 & 31.90 & 0.95 & 0.33 & 0.82 & 0.39 & Moderada \\
\hline & & Junio & $7,573,805$ & 67.20 & 16.46 & 28.67 & 0.95 & 0.33 & 0.84 & 0.37 & Moderada \\
\hline \multirow[t]{3}{*}{43} & \multirow[t]{3}{*}{ Comercio al por mayor } & Abril & $1,520,623$ & 56.66 & 17.49 & 21.81 & 0.94 & 0.43 & 0.83 & 0.32 & Moderada \\
\hline & & Mayo & $1,334,102$ & 57.86 & 19.41 & 23.44 & 0.94 & 0.42 & 0.81 & 0.34 & Moderada \\
\hline & & Junio & $1,687,541$ & 58.59 & 20.26 & 22.89 & 0.94 & 0.41 & 0.80 & 0.34 & Moderada \\
\hline \multirow[t]{3}{*}{46} & \multirow[t]{3}{*}{ Comercio al por menor } & Abril & $5,690,239$ & 75.26 & 20.50 & 46.74 & 0.93 & 0.25 & 0.79 & 0.47 & Moderada \\
\hline & & Mayo & $6,246,659$ & 61.77 & 22.18 & 57.99 & 0.93 & 0.38 & 0.78 & 0.47 & Moderada \\
\hline & & Junio & $7,313,419$ & 63.87 & 27.46 & 57.76 & 0.93 & 0.36 & 0.73 & 0.50 & Alta \\
\hline \multirow[t]{3}{*}{$48-49$} & \multirow{3}{*}{$\begin{array}{l}\text { Transportes, correos y } \\
\text { almacenamiento }\end{array}$} & Abril & $2,130,088$ & 70.22 & 41.75 & 56.79 & 0.92 & 0.30 & 0.58 & 0.56 & Alta \\
\hline & & Mayo & $2,392,434$ & 63.65 & 41.01 & 64.71 & 0.92 & 0.36 & 0.59 & 0.56 & Alta \\
\hline & & Junio & $1,997,264$ & 55.85 & 45.97 & 54.58 & 0.92 & 0.44 & 0.54 & 0.52 & Alta \\
\hline \multirow[t]{3}{*}{51} & \multirow{3}{*}{$\begin{array}{l}\text { Información en medios } \\
\text { masivos }\end{array}$} & Abril & 408,902 & 55.12 & 44.02 & 15.57 & 0.91 & 0.45 & 0.56 & 0.38 & Moderada \\
\hline & & Mayo & 268,625 & 41.40 & 10.81 & 24.72 & 0.91 & 0.59 & 0.89 & 0.26 & Moderada \\
\hline & & Junio & 404,901 & 46.41 & 22.34 & 11.42 & 0.91 & 0.54 & 0.78 & 0.27 & Moderada \\
\hline \multirow[t]{3}{*}{52} & & Abril & 739,964 & 45.56 & 16.75 & 6.55 & 0.90 & 0.54 & 0.83 & 0.23 & Moderada \\
\hline & alquiler de bienes & Mayo & 555,156 & 22.84 & 20.85 & 9.78 & 0.90 & 0.77 & 0.79 & 0.18 & Baja \\
\hline & & Junio & 496,787 & 31.31 & 21.80 & 3.93 & 0.90 & 0.69 & 0.78 & 0.19 & Baja \\
\hline
\end{tabular}

Fuente: Elaboración propia con base en datos mensuales correspondientes al segundo trimestre de la ETOE 2020. INEGI 
Continuación

\begin{tabular}{|c|c|c|c|c|c|c|c|c|c|c|c|}
\hline \multirow{2}{*}{$\begin{array}{l}\text { Clave } \\
\text { SCIAN }\end{array}$} & \multirow{2}{*}{$\begin{array}{l}\text { Sector de Actividad } \\
\text { Económica }\end{array}$} & \multirow[t]{2}{*}{ Mes } & \multirow[t]{2}{*}{ Total } & \multicolumn{3}{|c|}{ Porcentaje de población ocupada: } & \multicolumn{3}{|c|}{ Dimensiones } & \multirow[b]{2}{*}{ IPRE } & \multirow[b]{2}{*}{$\begin{array}{l}\text { Grado de } \\
\text { precariedad }\end{array}$} \\
\hline & & & & $\begin{array}{l}\text { Con ingresos de } \\
\text { hasta dos salarios } \\
\text { mínimos } \\
\end{array}$ & $\begin{array}{l}\text { Con jornada } \\
\text { de } 49 \text { horas o } \\
\text { más } \\
\end{array}$ & $\begin{array}{l}\text { Sin } \\
\text { prestaciones }\end{array}$ & 1 & 2 & 3 & & \\
\hline \multirow[t]{3}{*}{53} & \multirow{3}{*}{$\begin{array}{l}\text { Servicios inmobiliarios y de } \\
\text { alquiler de bienes }\end{array}$} & Abril & 324,932 & 67.17 & 22.80 & 44.45 & 0.89 & 0.33 & 0.77 & 0.45 & Moderada \\
\hline & & Mayo & 345,548 & 49.59 & 16.43 & 31.38 & 0.89 & 0.50 & 0.84 & 0.32 & Moderada \\
\hline & & Junio & 293,008 & 68.66 & 8.21 & 52.96 & 0.89 & 0.31 & 0.92 & 0.43 & Moderada \\
\hline \multirow[t]{3}{*}{54} & \multirow{3}{*}{$\begin{array}{l}\text { Servicios profesionales, } \\
\text { científicos y técnicos }\end{array}$} & Abril & $1,027,685$ & 40.29 & 6.08 & 48.05 & 0.88 & 0.60 & 0.94 & 0.31 & Moderada \\
\hline & & Mayo & 865,279 & 50.58 & 9.20 & 56.04 & 0.88 & 0.49 & 0.91 & 0.39 & Moderada \\
\hline & & Junio & $1,256,554$ & 29.67 & 9.01 & 45.17 & 0.88 & 0.70 & 0.91 & 0.28 & Moderada \\
\hline \multirow[t]{3}{*}{55} & \multirow[t]{3}{*}{ Corporativos } & Abril & 31,784 & 10.90 & 23.27 & - & 0.87 & 0.89 & 0.77 & 0.11 & Baja \\
\hline & & Mayo & 13,468 & 8.61 & 11.02 & - & 0.87 & 0.91 & 0.89 & 0.07 & Baja \\
\hline & & Junio & 24,295 & 3.06 & 31.97 & - & 0.87 & 0.97 & 0.68 & 0.12 & Baja \\
\hline \multirow[t]{3}{*}{56} & \multirow{3}{*}{$\begin{array}{l}\text { Servicios de apoyo a los } \\
\text { negocios y manejo de } \\
\text { desechos }\end{array}$} & Abril & $1,613,916$ & 68.21 & 29.01 & 20.34 & 0.86 & 0.32 & 0.71 & 0.39 & Moderada \\
\hline & & Mayo & $1,322,568$ & 75.36 & 26.80 & 18.41 & 0.86 & 0.25 & 0.73 & 0.40 & Moderada \\
\hline & & Junio & $1,579,422$ & 71.75 & 22.87 & 29.53 & 0.86 & 0.28 & 0.77 & 0.41 & Moderada \\
\hline \multirow[t]{3}{*}{61} & \multirow[t]{3}{*}{ Servicios educativos } & Abril & $1,960,599$ & 28.20 & 2.76 & 6.15 & 0.85 & 0.72 & 0.97 & 0.12 & Baja \\
\hline & & Mayo & $2,016,075$ & 23.45 & 9.08 & 9.76 & 0.85 & 0.77 & 0.91 & 0.14 & Baja \\
\hline & & Junio & $2,758,917$ & 28.63 & 5.13 & 9.29 & 0.85 & 0.71 & 0.95 & 0.14 & Baja \\
\hline \multirow[t]{3}{*}{62} & \multirow{3}{*}{$\begin{array}{l}\text { Servicios de salud y de } \\
\text { asistencia social }\end{array}$} & Abril & $1,214,881$ & 40.33 & 16.97 & 24.45 & 0.84 & 0.60 & 0.83 & 0.27 & Moderada \\
\hline & & Mayo & $1,324,173$ & 29.49 & 7.25 & 26.33 & 0.84 & 0.71 & 0.93 & 0.21 & Moderada \\
\hline & & Junio & $1,378,945$ & 30.70 & 10.18 & 20.50 & 0.84 & 0.69 & 0.90 & 0.20 & Moderada \\
\hline \multirow[t]{3}{*}{71} & \multirow{3}{*}{$\begin{array}{l}\text { Servicios de esparcimiento, } \\
\text { culturales y deportivos }\end{array}$} & Abril & 151,878 & 46.49 & 2.88 & 40.79 & 0.83 & 0.54 & 0.97 & 0.30 & Moderada \\
\hline & & Mayo & 140,024 & 58.77 & 7.51 & 22.55 & 0.83 & 0.41 & 0.92 & 0.30 & Moderada \\
\hline & & Junio & 258,835 & 47.01 & 27.55 & 23.90 & 0.83 & 0.53 & 0.72 & 0.33 & Moderada \\
\hline \multirow[t]{3}{*}{72} & \multirow{3}{*}{$\begin{array}{l}\text { Servicios de hospedaje y de } \\
\text { preparación de alimentos y } \\
\text { bebidas }\end{array}$} & Abril & $2,520,004$ & 75.54 & 16.99 & 60.80 & 0.82 & 0.24 & 0.83 & 0.51 & Alta \\
\hline & & Mayo & $2,986,218$ & 62.63 & 12.74 & 68.83 & 0.82 & 0.37 & 0.87 & 0.48 & Moderada \\
\hline & & Junio & $3,019,343$ & 69.74 & 15.57 & 68.80 & 0.82 & 0.30 & 0.84 & 0.51 & Alta \\
\hline \multirow[t]{3}{*}{81} & \multirow{3}{*}{$\begin{array}{l}\text { Otros servicios, excepto } \\
\text { actividades gubernamentales }\end{array}$} & Abril & $4,872,054$ & 80.19 & 9.96 & 65.31 & 0.81 & 0.20 & 0.90 & 0.52 & Alta \\
\hline & & Mayo & $4,511,861$ & 81.28 & 11.64 & 71.45 & 0.81 & 0.19 & 0.88 & 0.55 & Alta \\
\hline & & Junio & $5,281,624$ & 86.44 & 19.53 & 67.95 & 0.81 & 0.14 & 0.80 & 0.58 & Alta \\
\hline \multirow[t]{3}{*}{93} & & Abril & $3,383,811$ & 25.66 & 25.16 & 4.10 & 0.80 & 0.74 & 0.75 & 0.18 & Baja \\
\hline & gubernamentales y de & Mayo & $3,340,070$ & 22.96 & 23.69 & 3.38 & 0.80 & 0.77 & 0.76 & 0.17 & Baja \\
\hline & organismos internacionales & Junio & $2,731,086$ & 31.14 & 21.98 & 5.03 & 0.80 & 0.69 & 0.78 & 0.19 & Baja \\
\hline
\end{tabular}

Elaboración propia con base en datos mensuales correspondientes al segundo trimestre de la ETOE 2020. INEGI 
Durante los meses de confinamiento social obligatorio, parece ser que los empleos que se precarizaron fueron aquellos con trabajadores que cuentan con bajas credenciales educativas, considerados los más vulnerables, situación que coincide con las ideas de Ionescu (2012), quién señala que cuanto mayor educación tenga una persona, mayores son las posibilidades de conseguir un tabajo estable, por su parte, Arrizabalo, Pinto, y Vicent (2019); dicen que la precariedad laboral es un fenómeno universal ligado a las demandas actuales de acumulación capitalista, es decir, la educación no es un determinante que influye significativamente en la precarización. En nuestro caso, la evidencia estadística no es concluyente sobre la relación educación y precariedad laboral, se pensaría que sectores donde existe mayor PO con nivel de escolaridad medio y superior, el grado de precariedad es bajo y viceversa, sin embargo, como se observa en la figura 5, la tendencia del indice de precariedad es ascendente en el tiempo (tres meses de estudio) y heterogénea en el espacio (sectores).

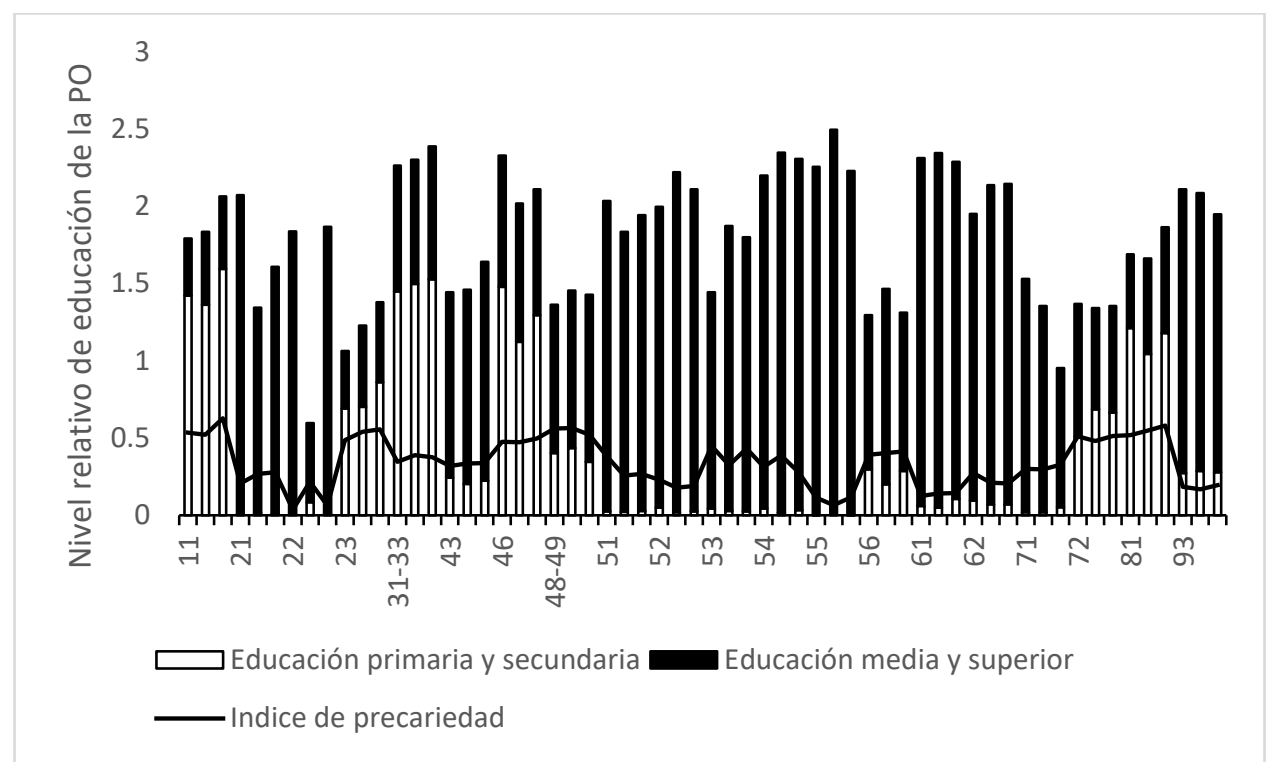

Figura 5. Relación entre nivel relativo de la educación de la PO y los sectores de actividad económica

Fuente: Elaboración propia con base en datos mensuales correspondientes al segundo trimestre de la ETOE 2020. INEGI

Masdonati, Fedrigo, y Zufferey, (2020), encuentran que contar con un trabajo precario no solo implica condiciones hostiles en el puesto sino, además, las aspiraciones educativas para los trabajadores precarios se tornan cada vez más complejas, es decir, la

A continuación, se presenta la dependencia estadística entre el grado de precariedad laboral y la educación, a través del desarrollo de un modelo econométrico tipo panel (información en el tiempo y en el espacio), con el propósito de evaluar si el nivel de educación de la población ocupada es un factor de incidencia de la precariedad laboral en los 20 sectores de actividad económica de México, durante los meses de abril, mayo y junio del 2020. Con el fin de no incurrir en sesgos de especificación, ni de estimación del modelo, se desarrollaron las pruebas correspondientes al análisis de datos tipo panel: efectos fijos, efectos aleatorios análisis de homocedasticidad y de no 
autocorrelación serial; con ello se busca conseguir los Mejores Estimadores Lineales Insesgados (MELI), que expliquen el fenómeno a estudiar.

Estas pruebas se realizaron recurriendo al paquete estadístico STATA versión 16, al siguiente modelo:

$$
\text { iprecal }_{i t}=\alpha+\beta_{1 t} e s c_{-} 1+\beta_{2 t} e s c_{-} 2+u_{i t}
$$

Dónde:

iprecal $_{i t}$ : Índice de precariedad laboral del sector $i$ en el tiempo $t$

$\alpha, \beta$ : Coeficiente de regresión

esc_1: Número de trabajadores con primaria incompleta y hasta educación secundaria del sector $i$ en el tiempo $t$.

esc_2: Número de trabajadores con educación media superior y superior del sector $i$ en el tiempo $t$ $u_{i t}$ : Termino de error aleatorio

Tabla 3. Test de Hausmant

\begin{tabular}{|l|c|c|c|c|}
\hline & \multicolumn{4}{|c|}{ Coeficientes } \\
\hline Variable & (b) Fijos & (B) Aleatorios & (b-B) Diferencia & Error estándar \\
\hline esc_1 & $3.86 \times 10^{-8}$ & $6.74 \times 10^{-8}$ & $-2.89 \times 10^{-8}$ & $3.06 \times 10^{-8}$ \\
\hline esc_2 & $8.54 \times 10^{-9}$ & $-3.73 \times 10^{-8}$ & $4.59 \times 10^{-8}$ & $3.06 \times 10^{-8}$ \\
\hline
\end{tabular}

$\mathrm{b}=$ consistente bajo Ho y Ha; $\mathrm{B}=$ inconsistente bajo Ha, eficiente bajo Ho

prueba: Ho: diferencia en coeficientes no sistemático

$\operatorname{chi}^{2}(2)=(b-B) '\left[\left(V_{-} b-V_{-} B\right)^{\wedge}(-1)\right](b-B)=2.45$

Prob $>$ chi $^{2}=0.2936$

Fuente: Elaboración propia a través del paquete STATA

El resultado del test de Hausmant presentado en la tabla 3, es estadísticamente no significativo de acuerdo con el valor del p-value (0.2936), lo que indica que no es posible rechazar la hipótesis nula de que la diferencia entre los coeficientes de efectos fijos y aleatorios es sistemática, por tanto, es conveniente utilizar el método de efectos aleatorios. Gujarati y Porter (2009), señalan que el modelo de efectos aleatorios, supone que los valores del intercepto son una extracción aleatoria de una población mucho mayor, es decir, son diferentes en cada unidad transversal. El método tradicional de MCO supone que el valor del intercepto de regresión es el mismo para todos los sectores de actividad económica, sin embargo, puede ser que haya la necesidad de controlar el carácter individual de cada una de ellas.

Ahora consideraremos que $\alpha_{i}$ es una variable aleatoria, por tanto, definiremos a $\alpha_{i}=\alpha+e_{i}$, y la sustituimos en la ecuación número (3), tenemos:

$$
\text { iprecal }_{i t}=\alpha+\beta_{1 t} \text { esc_1 } 1+\beta_{2 t} \text { esc_ } 2+e_{i}+u_{i t}
$$

En la expresión (4), se observa que si la varianza de $\alpha_{i}$ es igual a cero, entonces no existe ninguna diferencia entre el modelo de MCO y el de efectos aleatorios. Basándonos en la prueba del multiplicador de Lagrange de Breusch y Pagan, la cual permite analizar las varianzas al modelo y comprobar la hipótesis de que no existen efectos aleatorios en nuestra propuesta, en la tabla 4, 
observamos que para nuestro caso se rechaza la hipótesis nula y por tanto existen diferencias en las varianzas, por lo que el modelo a estimar es el de efectos aleatorios expresado en la ecuación número (4).

Tabla 4. Prueba Breusch y Pagan: Multiplicador de Lagrange para efectos aleatorios

\begin{tabular}{|c|c|c|}
\hline Variable & Varianza & Desviación estándar \\
\hline Ipre & 0.0239269 & 0.1546831 \\
\hline E & 0.0017497 & 0.0418297 \\
\hline$U$ & 0.0110531 & 0.1051339 \\
\hline
\end{tabular}

Prueba: $\operatorname{Var}(\mathrm{u})=0 ; \operatorname{chibar}^{2}(01)=41.81 ; \operatorname{Prob}>\operatorname{chibar}^{2}=0.0000$

Fuente: Elaboración propia a través del paquete STATA

Por último, y con el fin de obtener que los estimadores de nuestro modelo sean MELI. Se requiere que los $u_{i}$ sean independientes entre sí y se distribuyan idénticamente con varianza constante $\sigma^{2}$, es decir, que no exista autocorrelación serial de orden uno, ni heteroscedasticidad. La autocorrelación serial de orden uno se analizó con el test de Pesaran el cual mostró que a pesar de las variaciones ocasionadas por la crisis sanitaria nuestros datos no presentan este problema (tabla 5), el p-value, (0.649) muestra que no es posible rechazar la hipótesis nula de no autocorrelación serial de orden 1. Así mismo, para verificar la homocedasticidad de las varianzas se realiza el test modificado de Wald, el cual se presenta en la tabla 6. La hipótesis nula de este estadístico señala que no existe problemas de heteroscedasticidad, es decir, que las varianzas son constantes. Observando nuestros resultados podemos identificar que se rechaza la $\mathrm{H}_{0}$, por lo que nuestro modelo presenta un problema de heteroscedasticidad. Torres (2007), proponen corregir el problema de heteroscedasticidad utilizando el modelo con errores estándar robustos. ${ }^{4}$

Tabla 5. Test de Pesaran para evaluar la autocorrelación serial de orden 1

\begin{tabular}{|c|}
\hline Prueba de Pesaran de independencia transversal $=-0.850, \operatorname{Pr}=0.3951$ \\
\hline valor absoluto medio de los elementos fuera de la diagonal $=0.659$ \\
\hline
\end{tabular}

Fuente: Elaboración propia a través del paquete STATA

Tabla 6. Test de Wald modificado para evaluar la homocedasticidad de las variables en el modelo de regresión de efectos fijos

\begin{tabular}{|l|}
\hline H0: sigma $(i)^{\wedge} 2=$ para todo $i$ \\
\hline $\operatorname{chi}^{2}(20)=2710.38$ \\
\hline Prob $>$ chi $^{2}=0.0000$ \\
\hline
\end{tabular}

Fuente: Elaboración propia a través del paquete STATA

\footnotetext{
${ }^{4}$ Para un mayor análisis véase "Econometric Analysis of Cross Section and Panel Data" de Wooldridge (2002) y "Robust Standard Errors for Panel Regressions with Cross-Sectional Dependence" de Hoechle (2007).
} 
Una vez corregidos los problemas, en la tabla 7 se presentan los resultados del modelo. El signo positivo de la población ocupada con nivel de escolaridad de primaria trunca hasta secundaria indica que si este sector de la población aumenta la precariedad laboral se incrementará. Mientras que, la relación inversa entre población con educación media superior y superior y precariedad laboral, muestran que ante un incremento de la población con credenciales educativas de nivel medio superior y superior la precariedad laboral disminuye. Obsérvese la descomposición de la $\mathrm{R}^{2}$ en tres partes, en la primera se observa el peso que tienen las variables de educación para explicar la precariedad laboral en cada sector de actividad esta es de un $2.9 \%$, en la segunda, se refiere al peso para explicar la precariedad entre los sectores de actividad económica, la cual es del 53.59\% y de manera general las variables independientes explican el 50.94\% de la precariedad en las condiciones laborales. Es decir, la educación tiene un peso importante para determinar la precariedad laboral que se presentó en México durante los meses de confinamiento.

Tabla 7. Relación Empleo precario - educación, resultado de la estimación considerando efectos

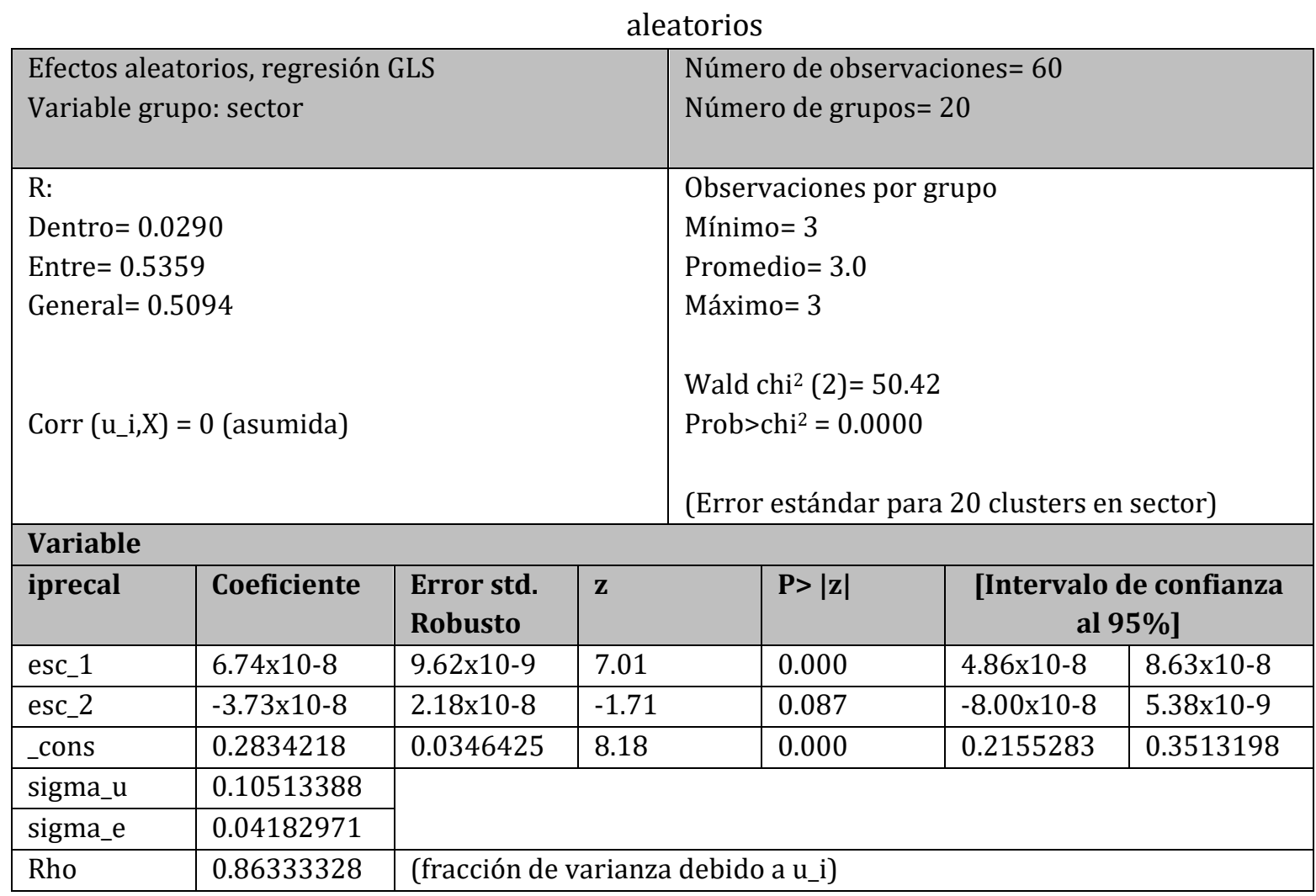

Fuente: Elaboración propia a través del paquete STATA

\section{Consideraciones finales}

Hablar de la pandemia por COVID-19 es hablar quizá del mayor reto al que se ha enfrentado la humanidad en los últimos años. Después de preservar la vida y la salud de sus ciudadanos, todo gobierno debe fomentar la creación de empleos dignos y de calidad, que permita a los trabajadores y sus familias vivir de manera decorosa. Este artículo presentó un breve recuento del impacto de la 
pandemia por COVID-19 en las condiciones de trabajo en México. En particular, analizó la relación entre el nivel de educación de los trabajadores mexicanos y la precarización de las condiciones laborales, en los primeros tres meses de la crisis sanitaria por la Covid-19. Se demuestra la existencia de una correlación estadística entre precariedad laboral y educación. De tal manera, que se verifica la hipótesis de trabajo la cual señala que los niveles de educación de la PO en México, estaban relacionados con la precariedad en las condiciones laborales que presentan los trabajadores.

El estudio muestra que la precarización de las condiciones laborales se agudizó con el confinamiento social que obligo al cierre de las actividades no esenciales, con el propósito de detener la propagación del virus SARS-CoV-2. Los resultados de esta acción fueron; de los poco más de 55 millones de trabajadores que existían en México durante el primer trimestre del año 2020, en los meses de abril, mayo y junio, 18.58\% perdieron su empleo, lo que representó que más de diez millones de trabajadores quedaran parados. Con la emergencia sanitaria los trabajadores que vivían en una situación de vulnerabilidad provocada por la precarización de sus condiciones laborales fueron los primeros en sentir los estragos de la pandemia, al perder su empleo y en la gran mayoría de los casos sin ninguna indemnización.

Por otro lado, la población que gana hasta 2 salarios mínimos se incrementó en 1.61 puntos porcentuales, lo que significa un empobrecimiento de la clase trabajadora. Otra característica de la pandemia fue la relación precariedad laboral-educación, pues los resultados presentados mostraron que los trabajadores que lograron mantener sus puestos de trabajo, fueron aquellos que tenían mejores credenciales educativas. El modelo desarrollado, mostró la existencia de una relación estadística significativa entre los niveles de educación y el índice de precariedad laboral. Así, existe evidencia estadística para señalar que la educación es un elemento importante para mejorar las condiciones laborales de los trabajadores.

Es importante dignificar el trabajo, para ello se requiere no solo la intervención del gobierno, sino también la voluntad de los propios empresarios para reconocer el carácter distributivo del salario. Además, el avance tecnológico a nivel mundial, obliga a tener trabajadores cada vez más preparados para satisfacer las necesidades de los nuevos puestos de trabajo, por ello, el gobierno federal y local, deben incentivar los mecanismos de cooperación entre las instituciones educativas y laborales, con el propósito de generar una sinergia que impulse la cooperación y colaboración entre ambas. El propósito es hacer que los trabajadores puedan desarrollar sus actividades bajo los esquemas que la nueva normalidad demanda, como son el comercio electrónico y el teletrabajo.

Por último, se requieren acciones inmediatas para mitigar los efectos de la pandemia sobre los trabajadores, por lo que la implementación de esquemas como el del seguro de desempleo, reducción de impuestos al trabajo y subsidios al salario, pueden ayudar a la población que la precarización de las condiciones de trabajo, ha situado como la más vulnerable. 


\section{Referencias}

[1] Anisi, D. (2005). La macroeconomía al comienzo del siglo XXI: una reflexión sobre el uso y posterior abandono del llamado keynesianismo. Principios. Estudios de Economía Política, 1 (1), 37-55. Recuperado de: https://fundacionsistema.com/wp-content/uploads/2015/05/Ppios1_D.-Anisi.pdf

[2] Arrizabalo, X., Pinto, P., \& Vicent, L. (2019). Historical Significance of Labor's Increased Precariousness in Germany, the United Kingdom, and Spain. The Americal Journal of Economics and Sociology, 78(1), 255-290. doi.org/10.1111/ajes.12266

[3] Campos-Vazquez, R.M., Esquivel, G. Consumption and geographic mobility in pandemic times. Evidence from Mexico. Rev Econ Household 19, 353-371 (2021). doi.org/10.1007/s11150-020-09539-2

[4] CEPAL. (2020). América Latina y el Caribe ante la pandemia del COVID-19. Efectos económicos y sociales. Serie Informe especial COVID-19, 1, 1-15. doi.org/10.18356/9789210054720

[5] Cimoli, M., y CEPAL. (2005). Heterogeneidad estructural, asimetrías tecnológicas y crecimiento en América Latina. Serie Documentos de proyectos, 35, 1-162. Recuperado de: https://repositorio.cepal.org/bitstream/handle/11362/2799/S2005051_es.pdf?sequence=1\&isAllo wed $=y$

[6] Cruz Martínez, A. (2020). SSA: se ha contratado a 42 mil médicos mexicanos y a 585 cubanos. La jornada, martes 16 de junio. Recuperado de: https://www.jornada.com.mx/ultimas/politica/2020/06/16/ssa-se-ha-contratado-a-42-milmedicos-mexicanos-y-a-585-cubanos-9579.html

[7] De Oliveira, 0. (2006). Jóvenes y precariedad laboral en México. Papeles de población, 12(49), 37-73. Recuperado de: https://rppoblacion.uaemex.mx/article/view/8660/7370

[8] Diario Oficial de la Federación, (2020). DOF 31 de marzo de 2020. Recuperado de https://www.dof.gob.mx/nota_detalle.php?codigo=5590914\&fecha=31/03/2020\&print=true

[9] Duncan, O. D., \& Duncan, B. (1955). A methodological analysis of segregation indexes. American sociological review, 20(2), 210-217. doi.org/10.2307/2088328

[10] Dutrénit, G. (2015, June). Políticas de innovación para fortalecer las capacidades en manufactura avanzada en México. Innovación tecnológica. Santiago de Chile: CIEPLAN. Recuperado de http://scioteca.caf.com/handle/123456789/772

[11] Encuesta Nacional de Ocupación y Empleo (2019). Información referente a la población de 15 años y más. Base de datos. Recuperado de: https://www.inegi.org.mx/programas/enoe/15ymas/default.html\#Tabulados

[12] Encuesta Telefónica de Ocupación y Empleo (2020). Información referente a la población de 15 años y más. Base de datos. Recuperado de: https://www.inegi.org.mx/investigacion/etoe/\#Microdatos

[13] Gálvez Santillán E., Gutiérrez Garza, E., y Picazzo Palencia E. (2011). El trabajo decente: nuevo paradigma para el fortalecimiento de los derechos sociales. Revista Mexicana de Sociología, 1(73), 73 104.

Recuperado de: http://revistamexicanadesociologia.unam.mx/index.php/rms/article/view/23564/22245

[14] García Guzmán, B. (2009). Los mercados de trabajo urbanos de México a principios del siglo XXI. Revista mexicana de sociología, 71(1), 5-46. Recuperado de http://revistamexicanadesociologia.unam.mx/index.php/rms/article/view/17742/16922

[15] Gurati, D. y Porter D. (2009). Basic Econometrics. New York, N.Y. United States. Mc Graw Hill.

[16] Hoechle, D. (2007). Robust Standard Errors for Panel Regressions with Cross-Sectional Dependence. The Stata Journal, 7 (3), 281-312. Doi: https://doi.org/10.1177/1536867X0700700301

[17] INEGI. (2021). Sistema de Clasificación Industrial de América del Norte 2018. Instituto Nacional de Estadística y Geografía: Recuperado de https://www.inegi.org.mx/app/scian/ 
REMEF (The Mexican Journal of Economics and Finance)

Efecto de la educación en la precarización del trabajo en tiempos de la COVID-19 en México

[18] Ionescu, A. M. (2012). How does education affect labour market outcomes. Review of Applied SocioEconomic Research, 4(2) 130-144

[19] Kaur, J. (2018). An Analysis of Occupational Gap: Duncan Dissimilarity Approach. Indian Journal of Economics and Development, 14 (1a), 479-485. DOI: 10.5958/2322-0430.2018.00100.2

[20] Llorente-Heras, R. (2020). Impacto del COVID-19 en el mercado de trabajo: un análisis de los colectivos vulnerables. Documentos de Trabajo (IAES, Instituto Universitario de Análisis Económico y Social), (2), 1-29. Recuperado de http://www.iaes.es/uploads/2/0/8/6/20860996/dt_02_20.pdf

[21] López Ahumada, E. (2020). Flexibilidad, protección del empleo y seguridad social durante la pandemia global del Covid-19. Documentos de trabajo IELAT, 134. Recuperado de: https://dialnet.unirioja.es/servlet/articulo?codigo=7393704

[22] Martínez-Licerio, K., Marroquín-Arreola, J., y Ríos-Bolivar, H. (2019). Precarización Laboral y pobreza en México. Análisis Xxiv (86), 113-131. doi.org/10.24275/uam/azc/dcsh/ae/2019v34n86/martinez

[23] Masdonati , J., Fedrigo, L., \& Zufferey, R. (2020). Emerging Job Precariousness: Work Experiences and Expectations of Low-Qualified Young Workers in Switzerland. Emerging Adulthood, 1-11. doi.org/10.1177/2167696820933730

[24] Melamed Varela, E., y Miranda Medina, C. (2016). Transferencia Tecnológica en la Educación. Educación y Humanismo, 180-185. doi.org/10.17081/eduhum.18.31

[25] Mendoza-González, M., Cruz-Calderón, S., y Valdivia-López, M. (2020). Niveles y subniveles de precariedad extrema en México: una metodología de grupos con condiciones laborales ordenadas. Estudios demográficos y urbanos, 35(2), 405-448. dx.doi.org/10.24201/edu.v35i2.1784

[26] Monroy, J. (2020). Ejército seguirá en tareas de seguridad, por decreto. El economista 11 de mayo. Recuperado de: https://www.eleconomista.com.mx/politica/AMLO-ordena-a-las-Fuerzas-Armadasauxiliar-a-la-Guardia-Nacional-en-materia-de-seguridad-publica-20200511-0043.html

[27] Organización Internacional del Trabajo. (2001). Panorama Laboral 2001 América Latina y el Caribe. Recuperado de OIT: https://www.ilo.org/wcmsp5/groups/public/---americas/---rolima/documents/publication/wcms_187554.pdf

[28] Organización Internacional del Trabajo. (1999). Informe y conclusiones de la decimocuarta Reunión Regional de los Estados Miembros de la OIT en las Américas. Recuperado de OIT: https://www.ilo.org/public/spanish/standards/relm/gb/docs/gb276/gb-

4.htm\#Protecci\%C3\%B3n\%20social

[29] Peiró, J., y Soler, A. (2020). El impulso al teletrabajo durante el COVID-19 y los retos que plantea. Estudio del Instituto Valenciano de Investigaciones Económicas. Universidad de Valencia. Recuperado de https://umivale.es/dam/web-corporativa/Documentos-prevenci-n-ysalud/11.Covid19IvieExpress.El-impulso-al-teletrabajo-durante-el-COVID-19-y-los-retos-queplanteaf.pdf

[30] Piketty, T. (2014). El capital en el siglo XXI. México: Fondo de Cultura Económica.

[31] Pineda Talavera, M. E. (2019). Honduras: precariedad laboral en la clase asalariada durante el modelo de acumulación neoliberal. Iconos. Revista de Ciencias Sociales (63), 101-123. DOI: 10.17141/iconos.63.2019.3421

[32] Rodríguez Juárez, E. (2018). Condiciones de trabajo y ganancias un análisis empírico de la economía mexicana 2009-2014. En D. Castro Lugo, M. Valdés Ibarra, \& A. V. Méndez Delgado, Economía Regional en México: perspectivas y avances (págs. 103-135). Monterrey N.L.: Ediciones De Laurel.

[33] Rodríguez Juárez, E., y Gaona Rivera, E. (2020). Una teoría de la Precariedad del trabajo: Marco analítico de la teoría de la inexistencia del mercado de trabajo. Pachuca, Hidalgo: UAEH.

[34] Rolle, P. (2005). El trabajo y su medida. En B. Lahire, P. Rolle, P. Saunier, M. Stroobants, M. Alaluf, y M. Postone, Lo que el trabajo esconde. Materiales para un replanteamiento de los análisis sobre el trabajo 
(págs. 119-130). Madrid: Traficante de Sueño. Recuperado de: https://www.traficantes.net/sites/default/files/pdfs/Lo\%20que\%20el\%20trabajo\%20escondeTdS.pdf

[35] Shrestha, N., Shad, M. Y., Ulvi, O., Khan, M. H., Karamehic-Muratovic, A., Nguyen, U. S. D., ... \& Haque, U. (2020). The impact of COVID-19 on globalization. One Health, 100180. doi.org/10.1016/j.onehlt.2020.100180

[36] Torres R. 0. (2007). Panel Data Analysis Fixed and Random. Effects Using Stata (v. 4.2). Data and statistical services. 1-40. Recuperado de https://www.princeton.edu/ otorres/Panel101.pdf

[37] Vázquez Rojas, A., y Rodríguez Juárez, E. (2020). La emergencia sanitaria y sus efectos en la economía de Hidalgo. En L. López Pontigo, O. Ávila Pozos, y G. I. Villegas de la Concha, La Universidad ante su compromiso educativo y social. Sus experiencias, retos y perspectivas frente a la pandemia generada por la COVID-19 (págs. 471-479). Pachuca: UAEH.

[38] Wooldridge J. (2002). Econometric Analysis of Cross Section and Panel Data. London, England: The MIT Press. 